\title{
Right low abdominal pain (RLAP): a new signal in food allergy
}

\author{
Isaac Azevedo Tenorio*, Aderbal Sabra, Selma Sabra \\ From 3rd WAO International Scientific Conference (WISC) 2014 \\ Rio de Janeiro, Brazil. 6-9 December 2014
}

\section{Objectives and study}

The objective of this study is to describe the pain in the right low abdominal area, i.e. , in the right iliac fossa, as a signal and symptom findings in the physical examination in patients with food allergy.

\section{Methods}

We studied the data of the physical examination of the right low abdômen área of 355 patients with food allergy, retrospective using the medical data from the medical records of the Brazilian Society of Food Allergy (SBAA).

\section{Results}

Our patients were $48 \%$ male and $52 \%$ female, and those numbers are not different from those of the pertinent literature. The age was distributed according with the literature, similar to all tree groups: $42.8 \%$ were infants, $32.7 \%$ were children ( 3 to 13 years) and $24.5 \%$ were adolescents and adults.

In anamneses of the GALT system, the abdominal pain was the most frequent complain, present in $15.6 \%$ of the patients, followed by diarrhea and vomits in 12.6 and constipation in $11.7 \%$, next to them we had vomiting in $11.7 \%$ of patients studied.

In the physical examination of the patients selected to the study, pain of the right inferior abdomen was present in $18 \%$ of patients followed by abdominal distension in $13.5 \%$. Left abdominal pain was found in $3.3 \%$. Epigastric pain and splenomegaly in $2.6 \%$.

\section{Conclusion}

One explanation for the RLAP in patients with food allergy is related to the ileal nodular lymphoidhyperplasia expressing the immunereaction at the Payers Patches in the terminal ileum. Another splanation to the pain is

\footnotetext{
Unigranrio, Brazil
} 